\title{
Rusty pipe syndrome: A case report
}

\author{
Usharani Thota, Vasudeva Murali Machiraju, Venkateswara Rao Jampana
}

Department of Paediatrics, Gandhi Medical College, Secunderabad, India;

dr.thotausha@gmail.com, vasudevamurali@gmail.com, dr_jvrao@yahoo.co.in

Received 6 October 2012; revised 10 November 2012; accepted 17 November 2012

\begin{abstract}
Bloody discharge from the breasts in a lactating woman can be caused by various conditions like cracked nipples, mastitis, trauma or ductal papilloma [1]. A physiological condition called rusty pipe syndrome can also cause bilateral bloody discharge in lactating mothers [2].
\end{abstract}

Keywords: Bloody Discharge from the Nipple; Rusty Pipe Syndrome

\section{INTRODUCTION}

Bleeding from nipples in a lactating mother can create anxiety in mother and the treating doctors. Bloody discharge from the breasts can be caused by various conditions like cracked nipples, mastitis, trauma or ductal papilloma [1]. Mastitis, cracked nipples and trauma are associated with pain. Ductal papilloma is usually unilateral. A physiological condition called rusty pipe syndrome can also cause bilateral bloody discharge in lactating mothers [2]. We report a case of Rusty pipe syndrome in a woman who delivered twin babies.

\section{CASE PRESENTATION}

A 21 yr old primigravida mother delivered twin babies in our hospoital. She started feeding the babies within one hour after birth. She was breast feeding both the babies. After $12 \mathrm{hr}$ mother noticed blood staining of both the babies' lips when she fed them. When she tried to express the milk there was bloody discharge from breasts (Figure 1). The resident of the postnatal ward got panicky and sent a call for the pediatrician. On evaluation by pediatrcian mother did not have any pain or swelling of the breasts. There was no history of trauma to the breasts. Examination of the breasts did not reveal any tenderness, engorgement or mass lesion. Both the nipples were normal and no cracks or fissures were noticed. There was frank bloody discharge from both the breasts. No colostrum secretion was noticed. Examination of babies' oral cavity did not reveal any natal teeth. As there were no signs of inflammation possibility of rusty pipe syndrome was considered and babies were put to breast to maintain lactation and additional formula milk was given by cup. Bloody discharge gradually decreased and by 5th postnatal day milk secretion started and babies were given exclusive breast feeds.

\section{DISCUSSION}

Rusty pipe syndrome is a physiological condition which causes transient painless bloody discharge from breasts [2]. This is usually bilateral but may begin in one breast first. This may be noticed during pregnancy but more common in early lactation. Rusty pipe syndrome occurs because of the increased vascularization of rapidly developing alveolae which have delicate network of capillaries. These capillaries get traumatized easily and result in bleeding from nipples. It is a painless condition which may come to notice when the mother expresses the milk or the infant vomits out blood, which tests positive for adult haemoglobin (Apt test) [1] or bloody staining of babies lips as happened in our case. Rusty-pipe syndrome is a self-limited condition and most cases clear within 3 to 7 days of onset of lactation [3]. Nipple manipulation should be discouraged. If the infant tolerates milk, breast feeding can continue during this period. The discharge should be evaluated if the bleeding persists for more than one week to exclude papillomas [1,4].

\section{CONCLUSION}

Rusty pipe syndrome is a physiological self limiting

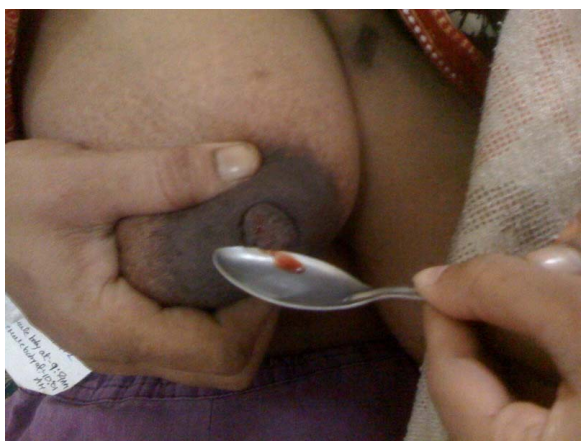

Figure. Bloody discharge from nipple. 
condition. Awareness of the medical and paramedical personnel dealing with lactating mothers about this benign condition is very much essential for proper management of this condition, to avoid unnecessary investigations and allaying anxiety in the mothers.

\section{REFERENCES}

[1] Lawrence, R.A. (2005) Breastfeeding: A guide for the medical profession. 6th Edition, Mosby, St. Louis, 473-
540.

[2] Verinderjit S.V., Jatinder, S.G. and Alka, K. (2001) Indian Pediatrics, 38, 931-932.

[3] Marianne, N. (2009) Great expectations: The essential guide to breastfeeding. Sterling Publishing Co., Inc., New York, 32

[4] Claire, M., William, S., Nancy, F.K. and Martha, S., (2000) The nursing mother's problem solver. Touchstone, New York, 248. 